Article

\title{
Development and Evaluation of a Duo Chikungunya Virus Real-Time RT-PCR Assay Targeting Two Regions within the Genome
}

\author{
Laurence Thirion ${ }^{1,+}$, Laura Pezzi ${ }^{1,2, \dagger}$, Iban Corcostegui ${ }^{1}$, Audrey Dubot-Pérès ${ }^{1}$, \\ Alessandra Falchi ${ }^{2}$, Xavier de Lamballerie ${ }^{1}$ and Remi N. Charrel ${ }^{1,3, * \text { (D) }}$ \\ 1 Unité des Virus Emergents (UVE: Aix Marseille Univ., IRD 190, INSERM 1207, IHU Méditerranée Infection), \\ 13005 Marseille, France \\ 2 EA7310, Laboratoire de Virologie, Université de Corse-Inserm, 94925 Corte, France \\ 3 Emerging Pathogens Institute, University of Florida, Gainesville, FL 32601, USA \\ * Correspondence: remi.charrel@univ-amu.fr \\ + These two authors contributed equally.
}

Received: 6 June 2019; Accepted: 12 August 2019; Published: 15 August 2019

check for updates

\begin{abstract}
Chikungunya virus (CHIKV) re-emerged as a globalized health threat fifteen years ago. There are dozens of RT-PCR assays published. An inventory of the latter was made, and after in silico analysis, two assays were selected for their ability to detect strains belonging to the five CHIKV genetic lineages. They were combined in order to provide a robust assay not affected by genetic point mutations and the resulting Duo CHIKV real-time RT-PCR assay was compared to the two parental single-plex tests against five strains belonging to the five genetic lineages. The Duo CHIKV assay performed equally, or better, in terms of sensitivity, specificity, linearity and signal intensity. Dual-target assays are better suited for viruses having the propensity to evolve into new variants via point mutations or major sequence deletions/insertions. Here, we demonstrated that combining two single systems into a dual-target assay did not impair sensitivity and specificity, and proved a potent diagnostic tool to face a potential emergence of CHIKV variants by newly evolving mutations.
\end{abstract}

Keywords: Alphavirus; Togaviridae; emergence; arbovirus; arthropod-borne; fever; epidemic; outbreak; tropical disease

\section{Introduction}

Fifteen years ago, Chikungunya virus (CHIKV) re-emerged as a global health threat because of its important human pathogenesis combined with its propensity for globalization. First identified in Tanzania in early 1952, it has caused periodic outbreaks in Asia and Africa since the 1960s [1]. The explosive outbreaks in the Indian Ocean, South-East Asia (2005-2007) and in the Americas (2013-2016) allowed the spread of the disease over a wider range, with more than five million cases over the last 15 years [2,3]. Recently, locally-acquired cases of CHIKV infection have been identified in Italy and France [4-7], proving that Europe has suitable conditions for the autochthonous transmission of CHIKV.

Chikungunya disease causes a dengue-like syndrome, characterized by fever, rash and arthralgia. This clinical picture does not allow to distinguish CHIKV infection from other pathogens causing similar illnesses (o'nyong-nyong virus, Mayaro virus, Dengue virus) based on clinical grounds [8]. Thus, laboratory identification of CHIKV infection has become an important issue for medical and epidemiological purposes. In particular, real-time PCR assays allow viral detection at the early stage of the infection, before the rise of IgM antibodies; they are the most frequently used technique used for routine diagnosis because of their sensitivity, specificity and short-turnaround time. 
This study aimed at compiling a list of all RT-qPCR assays available in literature in order to select the best suited for the detection of CHIKV strains belonging to the five genetic lineages, and to attempt to combine two of these assays into one in order to provide a test that is not only at least equally sensitive to the two parental ones, but also to provide a test that is more robust when facing possible false negatives due to point mutations or other evolutionary events frequently encountered with RNA genome viruses. To do so, (i) we performed in silico analysis for mismatch detection, (ii) we selected the two best suited RT-qPCR systems targeting different regions of the genome, (iii) we evaluated a combined Duo RT-qPCR assay against the two parental assays to assess the sensitivity of the Duo assay compared with that of the two parental assays individually, and the specificity against a panel of arboviruses that either belong to the genus Alphavirus or can be encountered in CHIKV epidemic and endemic areas, and are to be considered in the panel of agents for differential diagnosis.

\section{Materials and Methods}

\subsection{In Silico Analysis}

RT-qPCR assays for the diagnosis of CHIKV were searched for in NCBI PubMED CHIKV using "chikungunya" and "polymerase chain reaction" or "PCR" until December 2018. A total of 25 complete sequences representative of the five CHIKV genotypes (Asian, West African, East-Central-South African 1-3) were selected and aligned using MEGA 7 software. Primers and probes described in the literature were plotted against sequence alignment and compared for the number and position of mismatches. The choice of the two CHIKV RT-qPCR primers and probe sets to include in the Duo CHIKV RT-qPCR assay is discussed in the paragraph "Inventory of CHIKV RT-qPCR Assays and Selection" of the Results section.

\section{2. $R T-q P C R$}

RT-qPCR reactions for the two reference assays and the "designed in this study" Duo RT-qPCR were performed with SuperScript ${ }^{\circledR}$ III Platinum ${ }^{\circledR}$ One-Step RT-qPCR Kit with ROX (\#11732-088, Invitrogen-Thermo Fisher Scientific, Waltham, MA, USA) on a BioRad CFX96 ${ }^{\mathrm{TM}}$ thermal cycler, software version 3.1 (Bio-Rad Laboratories, Hercules, CA, USA). A $5 \mu \mathrm{L}$ volume of RNA was added to $20 \mu \mathrm{L}$ of mix containing $12.5 \mu \mathrm{L}$ of $2 \mathrm{X}$ Reaction Mix, $0.5 \mu \mathrm{L}$ of Superscript III RT/Platinum Taq Mix and primers and probe at the concentrations described in Table 1 . Cycling conditions were: $50^{\circ} \mathrm{C}$ for $30 \mathrm{~min} ; 95^{\circ} \mathrm{C}$ for $2 \mathrm{~min} ; 45$ cycles of $95^{\circ} \mathrm{C}$ for $15 \mathrm{~s}$ and $60^{\circ} \mathrm{C}$ for $45 \mathrm{~s}$. All probes were labeled with the same dye (FAM). There are no modifications for neither the sequence nor the concentrations of the primers and probes. The only difference is that the quencher of the probe described by Panning et al. has been modified for TAMRA, instead of BHQ in the original article. The reason for this is the need to have the same quencher for the probes of the two assays included in the Duo test.

Table 1. Primers and probes included in the Duo CHIKV RT-qPCR assay.

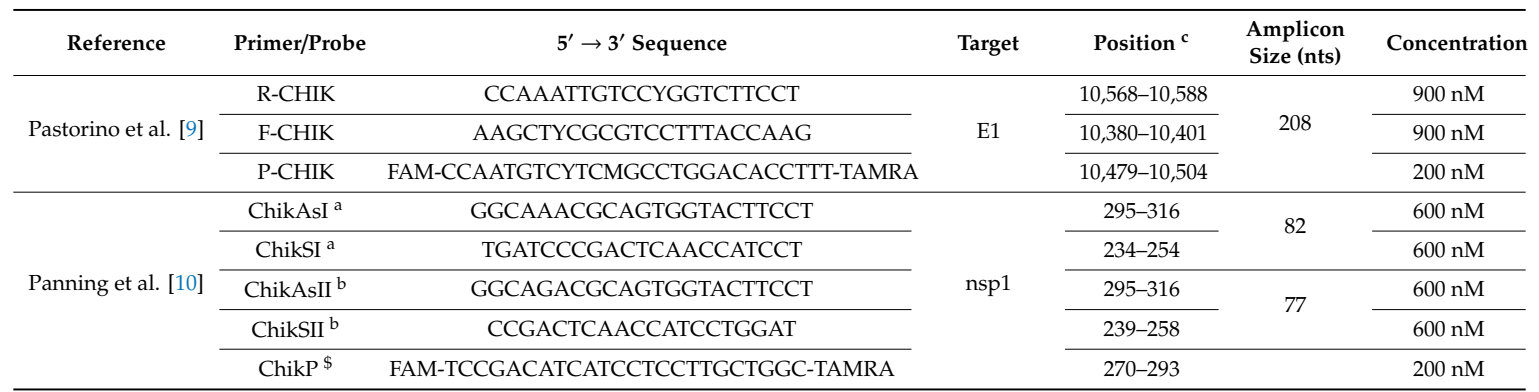

${ }^{\mathrm{a}}$ primer designed based on sequences of the five lineages; ${ }^{\mathrm{b}}$ primer designed from sequences of Indian Ocean strains; c refers to the sequence of Ross strain of CHIKV (ECSA1 lineage) (001v-EVA1455; GenBank acc no MG280943); nsp, non-structural protein; E1, envelope glycoprotein 1. \$, TAMRA quencher replaces the BHQ1 of the original study. 


\subsection{Generation of CHIKV RNA Synthetic Transcript}

A house-made synthetic standard RNA was used for the evaluation process of Duo CHIKV RT-qPCR assay, targeting one of the monoplex RT-qPCR included in the Duo assay. The target region, included in a plasmid synthetized by Genscript (GenScript, Piscataway, NJ, USA), was amplified by PCR. A first purification was performed using Monarch PCR \& DNA Cleanup Kit (New England BioLabs, Ipswich, MA, USA). The RNA transcript was synthetized in vitro by using MEGAshortscript ${ }^{\mathrm{TM}}$ T7 Transcription Kit (Invitrogen-Thermo Fisher Scientific, Waltham, MA, USA) according to the manufacturer's instructions. TURBO DNase included in the same kit was used to remove any residual DNA. The RNA transcript was purified using Monarch PCR \& DNA Cleanup Kit (New England BioLabs, Ipswich, MA, USA). The RNA concentration was determined using a Thermo Scientific ${ }^{\mathrm{TM}}$ NanoDrop ${ }^{\text {TM }}$ (Thermo Fisher Scientific, Waltham, MA, USA). The RNA transcript was serially diluted from $10^{8}$ to $10^{2}$ copies $/ \mu \mathrm{L}$, and dilutions were stored at $-80^{\circ} \mathrm{C}$.

\subsection{Sensitivity}

The measure and comparison of the sensitivity of the two selected assays and of the Duo assay was done with five strains of CHIKV representing the five genetic lineages: Asian, West African, and the three Eastern Central South African (ECSA 1, ECSA2, ECSA3), listed in Table 2. Serial dilutions of the quantitated freeze-dried cell culture supernatant were prepared using AVE buffer containing $1 \mu \mathrm{g} / \mathrm{mL}$ of RNA carrier (QIAGEN, Venlo, The Netherlands), in order to achieve 5-fold serial dilutions containing $10^{2}$ to $8.75 \times 10^{5}$ RNA copies $/ \mathrm{mL}$. Six decreasing concentrations were tested using six replicates for each. A Ct $\geq 40$ was considered as negative. LOD was defined as the number of RNA copies $/ \mu \mathrm{L}$ contained in the highest dilution for which all 6 replicates were positive.

\subsection{Specificity}

Pathogenic alphaviruses $(n=8)$, flaviviruses $(n=11)$ and phleboviruses $(n=3)$ were selected, and they are listed in Table 1 . All the viral strains included in the specificity panel were provided by European Virus Archive Goes Global (EVAg, https://www.european-virus-archive.com/), except Ross River virus, provided by the National Collection of Pathogenic Viruses (NCPV, https://www.pheculturecollections.org.uk/collections/ncpv.aspx). 
Table 2. Strains tested to assess specificity of Duo Chikungunya virus (CHIKV) RT-qPCR assay.

\begin{tabular}{|c|c|c|c|c|}
\hline Genus & \multicolumn{2}{|c|}{ Virus Species and Acronyms } & \multirow{2}{*}{$\begin{array}{c}\text { Strain (Viral Load TCID } 50 / \mathrm{mL}) \\
\text { UVE/CHIKV/1983/SN/WA } 37997\left(10^{6.22}\right)\end{array}$} & \multirow{2}{*}{$\frac{\text { Reference on EVAg or NCPV Catalog }}{001 \mathrm{~V}-02448 \text { (EVAg) }}$} \\
\hline \multirow{9}{*}{ Alphavirus } & \multirow{3}{*}{ Chikungunya virus } & CHIKV-West African & & \\
\hline & & CHIKV-ECSA1 & UVE/CHIKV/UNK/XX/ROSS $\left(10^{6.49}\right)$ & 001v-EVA1455 (EVAg) \\
\hline & & CHIKV-ECSA3 & UVE/CHIKV/2006/RE/LR2006_OPY1 $\left(10^{8.49}\right)$ & 001v-EVA83 (EVAg) \\
\hline & Mayaro virus & MAYV & UVE/MAYV/1954/TT/TC625 $\left(10^{8.82}\right)$ & 001v-EVA502 (EVAg) \\
\hline & O'nyong-nyong virus & ONNV & UVE/ONNV/UNK/SN/Dakar $234\left(10^{4.22}\right)$ & 001v-EVA1044 (EVAg) \\
\hline & Sindbis virus & SINV & UVE/SINV/UNK/EG/Egypt $339\left(10^{4.32}\right)$ & 001V-02469 (EVAg) \\
\hline & Western equine encephalitis virus & WEEV & UVE/WEEV/UNK/XX/47a $\left(10^{8.32}\right)$ & 001v-EVA1479 (EVAg) \\
\hline & Venezuelan equine encephalitis virus & VEEV & UVE/VEEV/UNK/XX/TC83 vaccine $\left(10^{9.42}\right)$ & 001v-EVA1459 (EVAg) \\
\hline & Eastern equine encephalitis virus & EEEV & UVE/EEEV/1999/XX/H178_99 $\left(10^{7.82}\right)$ & 001v-EVA1480 (EVAg) \\
\hline \multirow{7}{*}{ Flavivirus } & Zika virus & ZIKV & UVE/ZIKV/1947/UG/MR766 (10 4.32) & 001v-EVA143 (EVAg) \\
\hline & Dengue virus-1 & DENV-1 & UVE/DENV-1/2013/NC/CNR_17132 $\left(10^{7.57}\right)$ & 001V-03151 (EVAg) \\
\hline & West Nile virus & WNV & UVE/WNV/2008/US/R94224 (10 7.32) & 001V-02224 (EVAg) \\
\hline & Tick-borne encephalitis virus & TBEV & UVE/TBEV/2013/FR/32.11 WT-PCR $\left(10^{8.82}\right)$ & 001V-02355 (EVAg) \\
\hline & Yellow fever virus & YFV & UVE/YFV/UNK/XX/Vaccine strain 17D (10 $\left.{ }^{6.32}\right)$ & 001v-EVA67 (EVAg) \\
\hline & Saint Louis encephalitis virus & SLEV & UVE/SLEV/UNK/US/MSI-7 $\left(10^{4.82}\right)$ & 001v-EVA128 (EVAg) \\
\hline & Usutu virus & USUV & UVE/USUV/1959/ZA/SAAR-1776 $\left(10^{5.32}\right)$ & 001v-EVA138 (EVAg) \\
\hline \multirow{3}{*}{ Phlebovirus } & Toscana virus & TOSV & UVE/TOSV/2013/FR/113 $\left(10^{7.42}\right)$ & 001V-02461 (EVAg) \\
\hline & Rift Valley fever virus & RVFV & UVE/RVFV/UNK/XX/Smithburn vaccine $\left(10^{7.32}\right)$ & 001V-02385 (EVAg) \\
\hline & Sandly fever Sicilian virus & SFSV & UVE/SFSV/1943/IT/Sabin $\left(10^{6.82}\right)$ & 001v-EVA77 (EVAg) \\
\hline
\end{tabular}




\section{Results}

\subsection{CHIKV RT-qPCR Assays and Selection}

A total of seven assays were retrieved from the PubMED search [9-15]. Specific attention was given to mismatches located in the five nucleotides places at the $3^{\prime}$ extremity because of their ability to prevent correct hybridization. In probes, one or two mismatches generally do not compromise the hybridization potential but this also depends on the length of the probe and its $G+C$ content. When compared with the 25 sequence alignments, two assays clearly provided a lower number of mismatches and mismatches that were not located in critical position. Detailed analysis had also been performed in a recent article, the leading author of which is one author of this study [8]. The first system, (Pastorino et al., 2005) designed to detect CHIKV strains belonging to both African and Asian lineages, consists of two primers and one probe which are located at the 3' untranslated region [9]. Comparison with sequence alignment showed one possible mismatch within the forward primer with one strain belonging to the ECSA1 lineage at a position that is of little influence for hybridization (Figure 1). There was no mismatch within either the reverse primer or the probe. The second system, (Panning et al., 2006) consists of one fluorogenic probe and two sets of sense and reverse primers targeting the nsp1 gene: One set of primer is adapted to all CHIKV lineages, whereas the second one is best suited for strains belonging to the Indian Ocean lineage [10]. Few mismatches were observed in the in silico analysis, especially between the first couple of primers and ECSA3 strains sequences; however, the presence of a second set of primers complements the possible flaws of the first set (Figure 2).

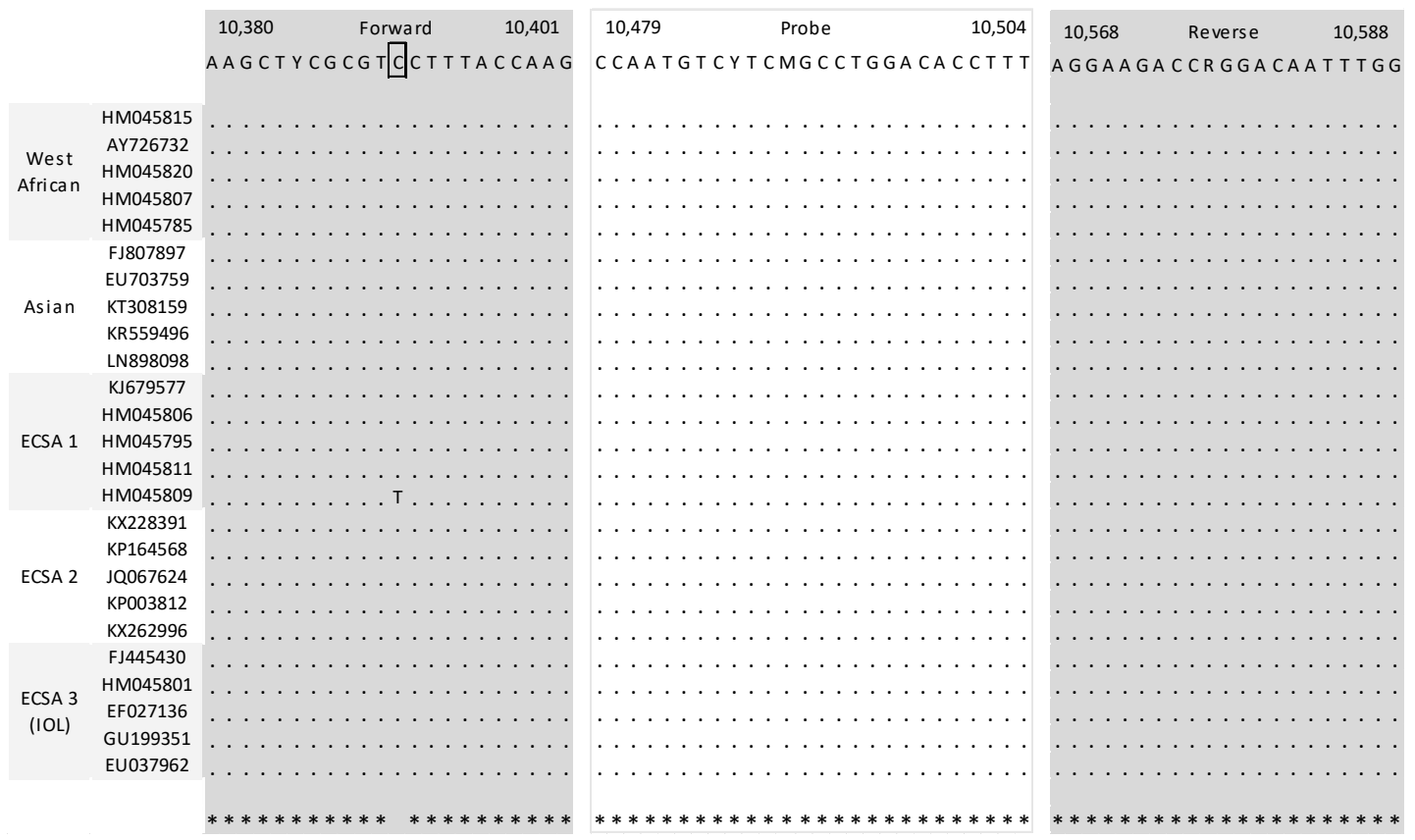

Figure 1. Mapping of primers and probe of selected systems described by Pastorino et al. Nucleotide positions refers to the sequence of Ross strain of CHIKV (ECSA1 lineage) (001v-EVA1455; GenBank accession number MG280943). 


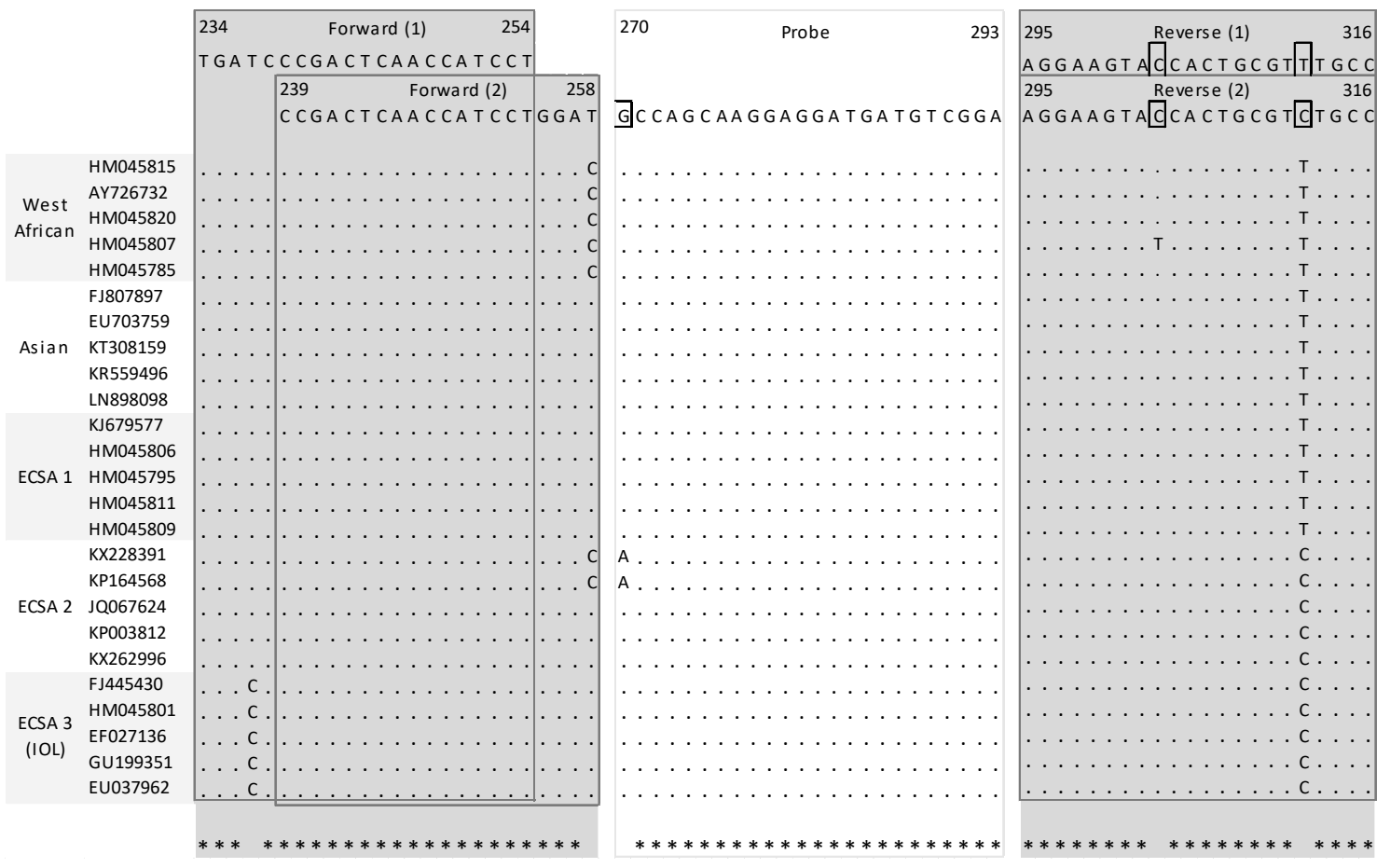

Figure 2. Mapping of primers and probe of selected systems described by Panning et al. Nucleotide positions refers to the sequence of Ross strain of CHIKV (ECSA1 lineage) (001v-EVA1455; GenBank accession number MG280943). (1) refers to primer sets common for all CHIKV lineages, (2) refers to the second set of primers that is targeting specifically strains belonging to the epidemic Indian Ocean lineage.

\subsection{Analytical Sensitivity of Duo CHIKV RT-qPCR Assay}

The results are presented in Table 3. With no exception, the Duo assay showed equal or better sensitivity compared to the two single assays. For Asian and ECSA2 strains, the Duo assay provided 6/6 for 8 and 13 RNA copies/ $\mu \mathrm{L}$ compared with 32 and 44 RNA copies $/ \mu \mathrm{L}$ with the two mono-target assays, respectively. For West African, ECSA1 and ECSA3 strains, both Duo and mono-target assays detected 6/6 replicates for 24,39 and 41 copies $/ \mu \mathrm{L}$, respectively. The Duo assay detected all strains with $6 / 6$ scores for copies with the number varying from 8 to 41 per $\mu \mathrm{L}$; the two single assays showed similar sensitivity with $6 / 6$ scores for $24-44$ RNA copies $/ \mu \mathrm{L}$.

\subsection{Specificity of Duo CHIKV RT-qPCR Assay}

The specificity of the assay was tested against several related and non-related viruses from Alphavirus, Flavivirus and Phlebovirus genera. The 22 strains incorporated in the panel correspond to viruses that are present in areas where CHIKV is circulating and to other alphaviruses distinct from CHIKV. Five CHIKV strains of different lineages were used as positive controls. Duo CHIKV RT-qPCR detected all CHIKV strains and did not react with the 22 viruses included in the exclusivity test panel, with a specificity of $100 \%$.

\subsection{Linearity of Duo CHIKV RT-qPCR vs. Pastorino and Panning Mono-Target Assays}

The results about the analytical sensitivity test obtained with the Duo CHIKV RT-qPCR test were compared to results of the mono-target assays, Pastorino and Panning (Table 3), in order to evaluate the correlation between $\mathrm{Ct}$ values and the six different CHIKV concentrations previously tested. The response $(\mathrm{Ct})$ for the three systems is linear, with correlation coefficient $\left(\mathrm{R}^{2}\right)$ close to one for all CHIKV strains. Results are detailed in Figure 3. 
Table 3. Analytical sensitivity of Duo CHIKV RT-qPCR, Pastorino and Panning assays.

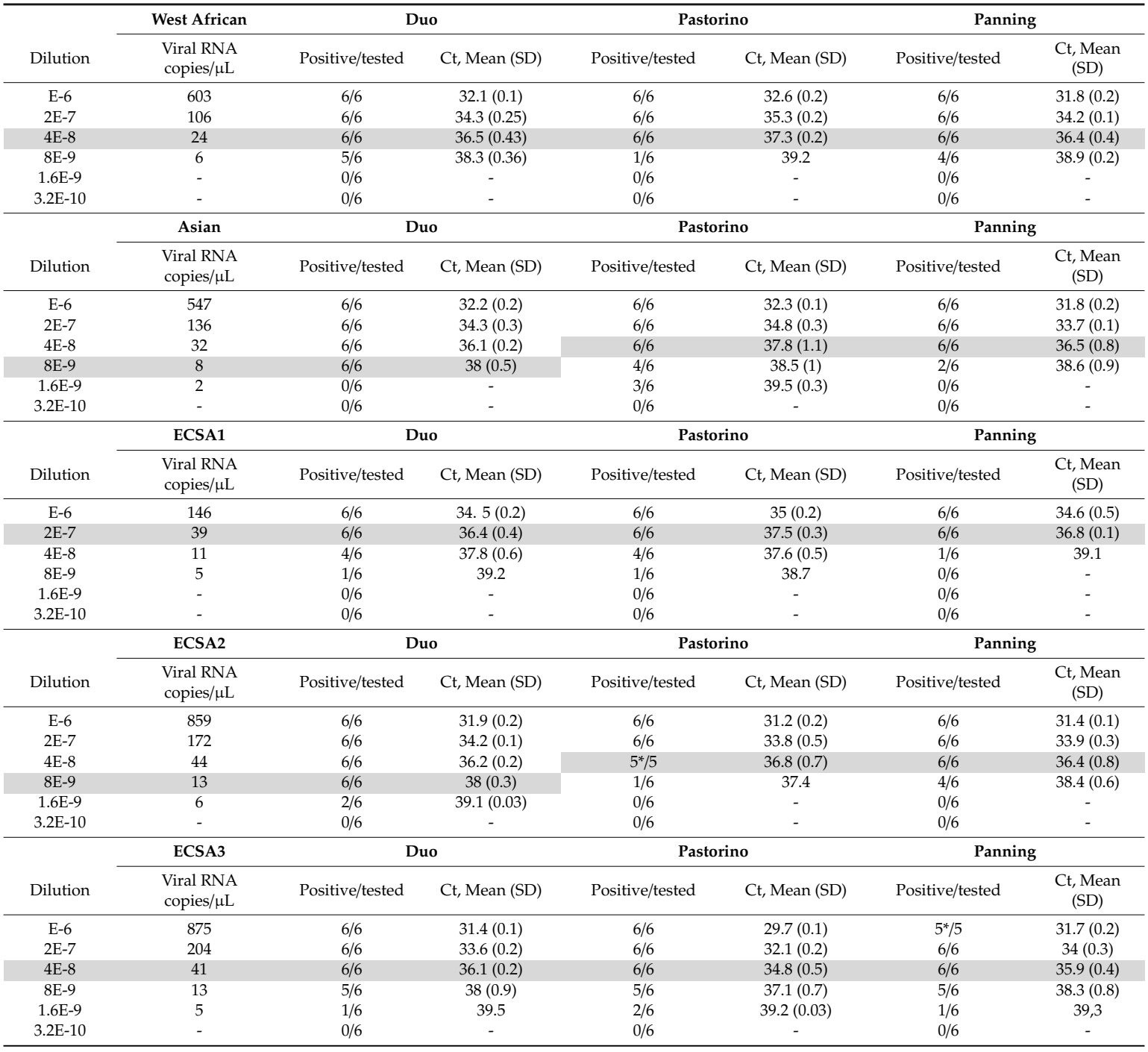

* one replicate was removed due to a manufacturing error. Pastorino corresponds to Reference [9] (3'UTR),

Panning correspond to Reference [10] (nsp1).

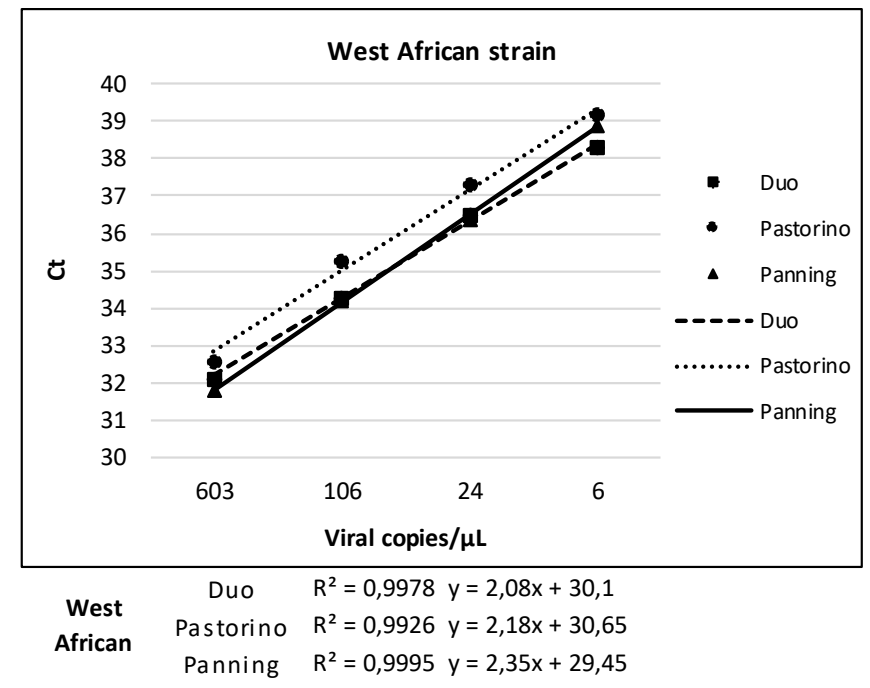

Figure 3. Cont. 

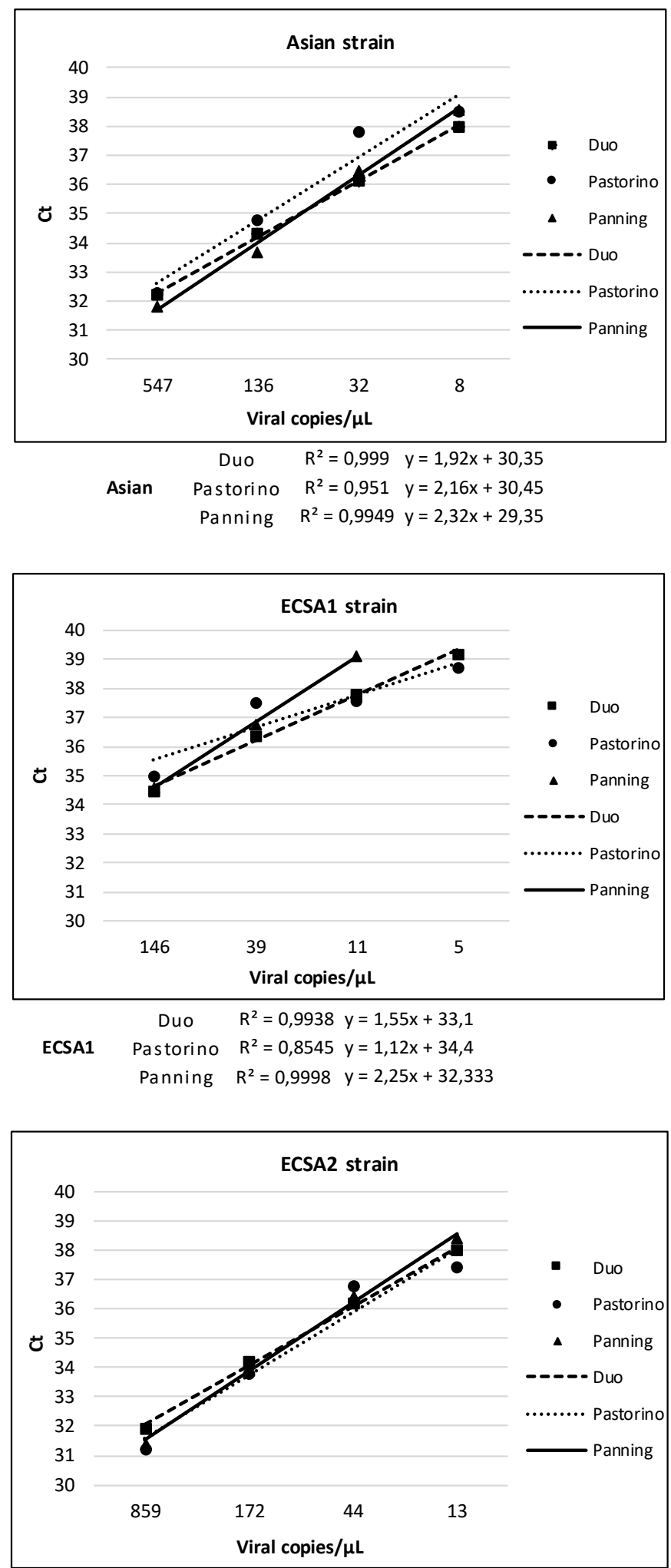

Duo $R^{2}=0,997 \quad y=2,03 x+30$

ECSA2 Pastorino $R^{2}=0,9437 y=2,16 x+29,4$

Panning $R^{2}=0,9973 y=2,35 x+29,15$

Figure 3. Cont. 


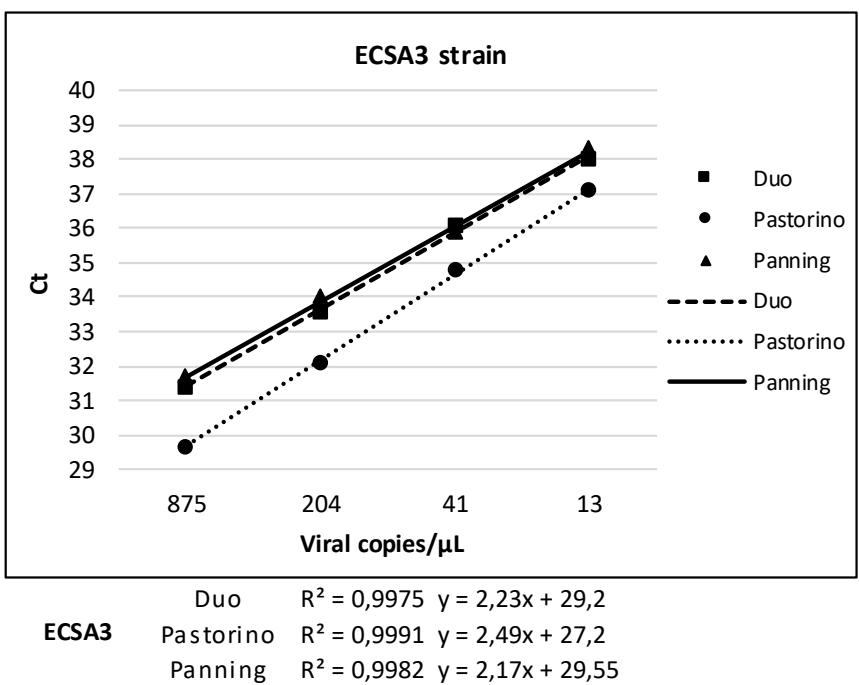

Figure 3. Linearity of Duo CHIKV RT-qPCR vs. Pastorino and Panning Mono-Target Assays.

\subsection{Signal Intensity}

Signal intensity is important for it has a significant impact on the ability to discriminate between negative and positive results without ambiguity. This situation is usually observed when the tested sample contains a low number of RNA copies, thus inducing a signal that is weak. As shown in Figure 4, low copy samples that are close to the limit of detection provide a much stronger signal with the Duo CHIKV RT-qPCR assay compared to mono-target assays.

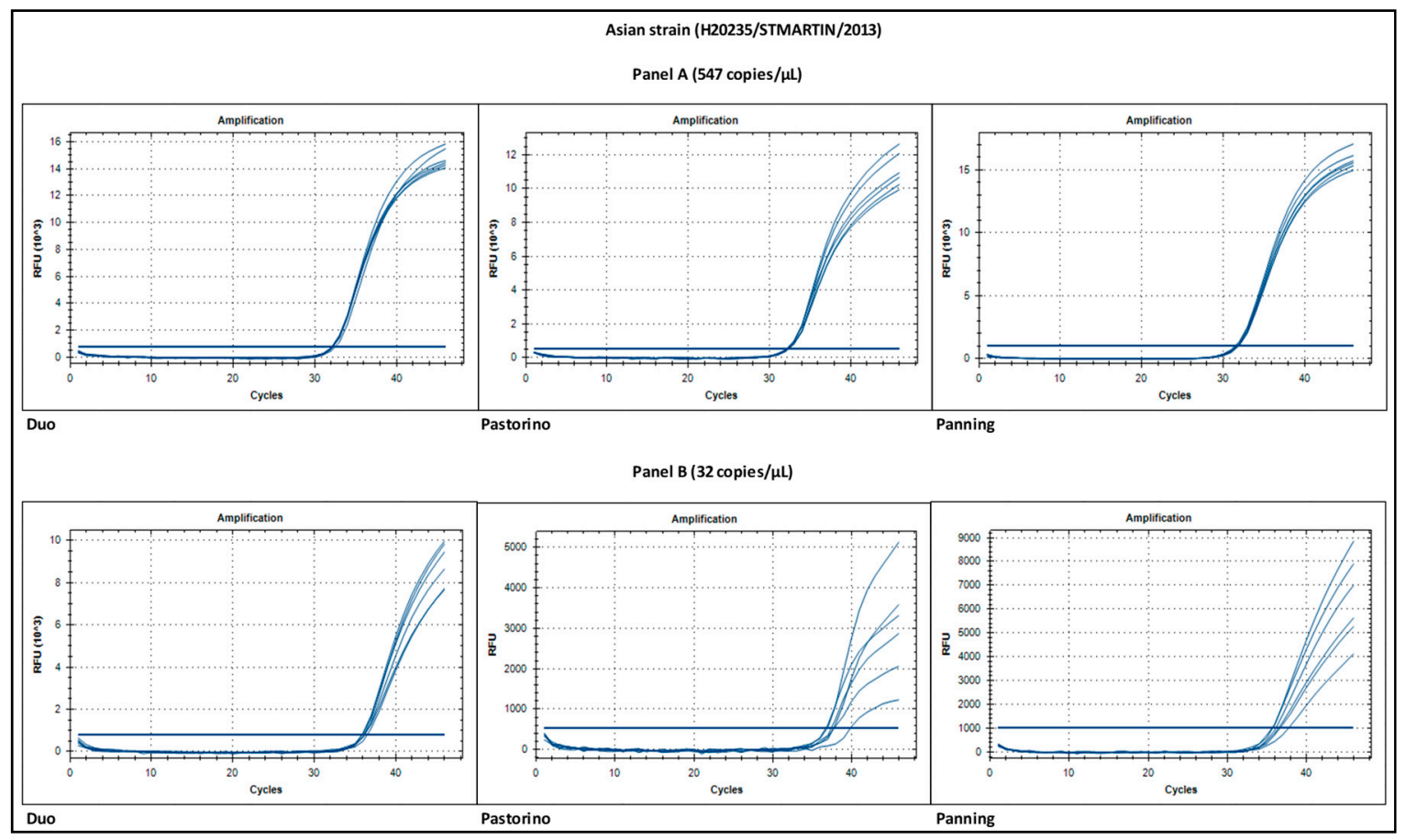

Figure 4. Intensity of fluorescence signal of CHIKV Asian strain at high (A) and low (B) RNA copy number.

\section{Discussion}

In this study, we developed and evaluated a Duo Chikungunya RT-qPCR assay; its dual-target design is characterized by the creation and detection of two different amplicons based on two different sets of primers and probes. Otherwise, we identified in literature several dual-target commercial tests for the screening of non-arboviral pathogens: Among them, Roche COBAS TaqMan HIV-1 assay 
(Roche Holding AG, Basel, Switzerland) and Hologic Aptima HIV-1 Assay (Hologic Inc, Marlborough, MA, USA) have been evaluated [16-18] and their use is recommended for blood donor screening test of HIV-1. In Germany, for example, from 1 January, 2015, the use of dual-target NATs is mandatory to screen cellular blood components, therapeutic individual plasma and stem cell preparations for hematopoietic re-constitution for HIV-1 [19]. This obligation was introduced after six cases of HIV-1 RNA-positive blood donations occurred between 2007 and 2012, despite routine NAT screening, of which two resulted in HIV transmission to the recipients by transfusion of the corresponding red blood cell (RBC) concentrates [20-23]. HIV-1 detection failures were due to mono-target assays measuring viral variants that exhibited mismatches with primer or probe sequences of the NAT target region.

The advantages of a dual-target design are multiple. Firstly, it allows us to detect viral genomes exhibiting mutations, as well as new viral variants. Polymorphisms, point mutations or major sequence deletions/insertions can compromise the accuracy of diagnostic and screening tests, resulting in false-negative NAT results despite viral RNA at concentration levels sufficiently high for detection by NAT. The inclusion of two targets into the assay design assures that the failure of one region detection is compensated by the detection of the other. This is of particular interest for CHIKV detection: Its potential to emerge and sustain its circulation in new environments relies on its ability to undergo genetic changes, in order to adapt to new hosts. In fact, the 2005-2006 epidemic in the Indian Ocean was associated with a strain of CHIKV with a mutation in the envelope protein gene (E1-A226V) [24,25]. Probability of CHIKV detection, compensating for mutations or mismatches, can be increased by the choice of two, well-conserved genome regions to be targeted by NAT tests.

Secondly, a dual-target design allows an easy interpretation of the results. The use of a unique fluorescent dye for both probes (as we chose for our Duo CHIKV RT-qPCR assay) provides a simple algorithm for the validation of the analytical results. A negative result corresponds to the lack of amplification by both assays; a positive result corresponds to the detection of a viral genome by either both assays or one assay only, without the possibility to distinguish the two situations, avoiding endless use of confirmatory assays. In the case of low copy samples close to the limit of detection, a cumulative curve with a much stronger signal is obtained with Duo CHIKV RT-qPCR assays compared to mono-target assays. This renders the technical validation of the assay truly easier; consequently, it reduces the number of inconclusive results that must imply to perform confirmation assays before final results, with increasing expenses and delayed results.

Thirdly, dual-target design can offer an improved sensitivity compared to mono-target assays. During acute infection with CHIKV, the observed levels of viremia are usually substantially higher than those observed with most other arboviruses, and specifically with flaviviruses [1,26-28]. Accordingly, although the question of sensitivity is less critical, we showed that the Duo assay sensitivity against strains representing the five main genetic lineages is at least equal and can be better than the sensitivity demonstrated by the single assays, individually.

\section{Conclusions}

As a conclusion, we demonstrated that combining two single systems into a dual-target assay do not impair sensitivity and specificity in CHIKV detection; moreover, it is a useful tool to face a potential emergency of CHIKV variants by newly evolving mutations. This study demonstrates that developing a Duo assay from two previously validated assays is easy and rapid. Thus, this study must be seen as a proof of concept that can be declined for other arboviruses and even other pathogens for providing a safe assay to be used routinely in clinical microbiology laboratories.

Author Contributions: Conceptualization, X.d.L., R.N.C.; methodology, L.T., I.C., A.D.-P.; validation, L.T., L.P., A.D.-P.; writing—original draft preparation, L.T., L.P.; writing—review and editing, R.N.C., X.d.L.; supervision, X.d.L., R.N.C.; funding acquisition, X.d.L., A.F.

Funding: This research was partly funded by (i) the European Virus Archive (European Union Seventh Framework Programme under grant agreement no. 228292) (http://www.european-virus-archive.com/), (ii) the European 
Virus Archive goes Global (EVAg) project that has received funding from the European Union's Horizon 2020 research and innovation programme under grant agreement No 653316, (iii) Université de Corse Pasquale Paoli, Corte, France (UCPP), (iv) Emerging Viral Diseases-Expert Laboratory Network (EVD-LabNet). L.P. is a PhD student granted by UCPP and INSERM.

Acknowledgments: The authors thank Gregory Molle and Soline Buisine for excellent technical assistance.

Conflicts of Interest: The authors declare no conflict of interest. The funders had no role in the design of the study; in the collection, analyses, or interpretation of data; in the writing of the manuscript, or in the decision to publish the results.

\section{References}

1. Thiberville, S.D.; Moyen, N.; Dupuis-Maguiraga, L.; Nougairede, A.; Gould, E.A.; Roques, P.; De Lamballerie, X. Chikungunya fever: Epidemiology, clinical syndrome, pathogenesis and therapy. Antivir. Res. 2013, 99, 345-370. [CrossRef] [PubMed]

2. Chikungunya. Available online: https://www.who.int/news-room/fact-sheets/detail/chikungunya (accessed on 26 April 2019).

3. PAHO; WHO. Chikungunya: Data, Maps and Statistics. Available online: https://www.paho.org/hq/index. php?option=com_topics\&view $=$ rdmore\&cid=5927\&item $=$ chikungunya\&type=statistics $\&$ Itemid $=40931 \&$ lang=en (accessed on 28 January 2019).

4. Delisle, E.; Rousseau, C.; Broche, B.; Leparc-Goffart, I.; L'ambert, G.; Cochet, A.; Prat, C.; Foulongne, V.; Ferre, J.B.; Catelinois, O.; et al. Chikungunya outbreak in Montpellier, France, September to October 2014. Eurosurveillance 2014, 20, 21108. [CrossRef]

5. Calba, C.; Guerbois-Galla, M.; Franke, F.; Jeannin, C.; Auzet-Caillaud, M.; Grard, G.; Pigaglio, L.; Decoppet, A.; Weicherding, J.; Savaill, M.-C.; et al. Preliminary report of an autochthonous chikungunya outbreak in France, July to September 2017. Eurosurveillance 2017, 22, 17-00647. [CrossRef] [PubMed]

6. Angelini, P.; Macini, P.; Finarelli, A.C.; Pol, C.; Venturelli, C.; Bellini, R.; Dottori, M. Chikungunya epidemic outbreak in Emilia-Romagna (Italy) during summer 2007. Parassitologia 2008, 50, 97-98. [PubMed]

7. Rezza, G. Chikungunya is back in Italy: 2007-2017. J. Travel. Med. 2018, 25, tay004. [CrossRef] [PubMed]

8. Pezzi, L.; Reusken, C.B.; Weaver, S.C.; Drexler, J.F.; Busch, M.; LaBeaud, A.D.; Diamond, M.S.; Vasilakis, N.; Drebot, M.A.; Siqueira, A.M.; et al. GloPID-R report on Chikungunya, O'nyong-nyong and Mayaro virus, part I: Biological diagnostics. Antivir. Res. 2019, 166, 66-81. [CrossRef]

9. Pastorino, B.; Bessaud, M.; Grandadam, M.; Murri, S.; Tolou, H.J.; Peyrefitte, C.N. Development of a TaqMan RT-PCR assay without RNA extraction step for the detection and quantification of African Chikungunya viruses. J. Virol. Methods 2005, 124, 65-71. [CrossRef]

10. Panning, M.; Grywna, K.; Van Esbroeck, M.; Emmerich, P.; Drosten, C. Chikungunya Fever in Travelers Returning to Europe from the Indian Ocean Region, 2006. Emerg. Infect. Dis. 2008, 14, 416-422. [CrossRef]

11. Lanciotti, R.S.; Kosoy, O.L.; Laven, J.J.; Panella, A.J.; Velez, J.O.; Lambert, A.J.; Campbell, G.L. Chikungunya Virus in US Travelers Returning from India, 2006. Emerg. Infect. Dis. 2007, 13, 764-767. [CrossRef] [PubMed]

12. Waggoner, J.J.; Ballesteros, G.; Gresh, L.; Mohamed-Hadley, A.; Tellez, Y.; Sahoo, M.K.; Abeynayake, J.; Balmaseda, A.; Harris, E.; Pinsky, B.A. Clinical evaluation of a single-reaction real-time RT-PCR for pan-dengue and chikungunya virus detection. J. Clin. Virol. 2016, 78, 57-61. [CrossRef]

13. Cecilia, D.; Kakade, M.; Alagarasu, K.; Patil, J.; Salunke, A.; Parashar, D.; Shah, P.S. Development of a multiplex real-time RT-PCR assay for simultaneous detection of dengue and chikungunya viruses. Arch. Virol. 2015, 160, 323-327. [CrossRef]

14. Smith, D.R.; Lee, J.S.; Jahrling, J.; Kulesh, D.A.; Turell, M.J.; Groebner, J.L.; O'Guinn, M.L. Development of Field-Based Real-Time Reverse Transcription-Polymerase Chain Reaction Assays for Detection of Chikungunya and O'nyong-nyong Viruses in Mosquitoes. Am. J. Trop. Med. Hyg. 2009, 81, 679-684. [CrossRef]

15. Edwards, C.J.; Welch, S.R.; Chamberlain, J.; Hewson, R.; Tolley, H.; Cane, P.A.; Lloyd, G. Molecular diagnosis and analysis of Chikungunya virus. J. Clin. Virol. 2007, 39, 271-275. [CrossRef] [PubMed]

16. Templer, S.P.; Seiverth, B.; Baum, P.; Stevens, W.; Seguin-Devaux, C.; Carmona, S. Improved Sensitivity of a Dual-Target HIV-1 Qualitative Test for Plasma and Dried Blood Spots. J. Clin. Microbiol. 2016, 54, 1877-1882. [CrossRef] 
17. Sizmann, D.; Glaubitz, J.; Simon, C.O.; Goedel, S.; Buergisser, P.; Drogan, D.; Hesse, M.; Kröh, M.; Simmler, P.; Dewald, M.; et al. Improved HIV-1 RNA quantitation by COBAS ${ }^{\circledR}$ AmpliPrep/COBAS TaqMan HIV-1 Test, v2.0 using a novel dual-target approach. J. Clin. Virol. 2010, 49, 41-46. [CrossRef] [PubMed]

18. Damond, F.; Avettand-Fenoel, V.; Collin, G.; Roquebert, B.; Plantier, J.C.; Ganon, A.; Sizmann, D.; Babiel, R.; Glaubitz, J.; Chaix, M.L.; et al. Evaluation of an Upgraded Version of the Roche Cobas AmpliPrep/Cobas TaqMan HIV-1 Test for HIV-1 Load Quantification. J. Clin. Microbiol. 2010, 48, 1413-1416. [CrossRef] [PubMed]

19. Chudy, M.; Kress, J.; Halbauer, J.; Heiden, M.; Funk, M.B.; Nübling, C.M. Risk Minimization Measures for Blood Screening HIV-1 Nucleic Acid Amplification Technique Assays in Germany. Transfus. Med. Hemother. 2014, 41, 45-51. [CrossRef] [PubMed]

20. Schmidt, M.; Korn, K.; Nübling, C.M.; Chudy, M.; Kress, J.; Horst, H.A.; Geusendam, G.; Hennig, H.; Sireis, W.; Rabenau, H.F.; et al. First transmission of human immunodeficiency virus Type 1 by a cellular blood product after mandatory nucleic acid screening in Germany. Transfusion 2009, 49, 1836-1844. [CrossRef]

21. Edelmann, A.; Kalus, U.; Oltmann, A.; Stein, A.; Unbehaun, A.; Drosten, C.; Krüger, D.H.; Hofmann, J. Improvement of an ultrasensitive human immunodeficiency virus type 1 real-time reverse transcriptase-polymerase chain reaction targeting the long terminal repeat region. Transfusion 2010, 50, 685-692. [CrossRef] [PubMed]

22. Chudy, M.; Weber-Schehl, M.; Pichl, L.; Jork, C.; Kress, J.; Heiden, M.; Funk, M.B.; Nübling, C.M. Blood screening nucleic acid amplification tests for human immunodeficiency virus Type 1 may require two different amplification targets. Transfusion 2012, 52, 431-439. [CrossRef]

23. Müller, B.; Nübling, C.M.; Kress, J.; Roth, W.K.; De Zolt, S.; Pichl, L. How safe is safe: new human immunodeficiency virus Type 1 variants missed by nucleic acid testing. Transfusion 2013, 53, 2422-2430. [CrossRef] [PubMed]

24. Tsetsarkin, K.A.; VanLandingham, D.L.; McGee, C.E.; Higgs, S. A Single Mutation in Chikungunya Virus Affects Vector Specificity and Epidemic Potential. PLoS Pathog. 2007, 3, e201. [CrossRef] [PubMed]

25. Schuffenecker, I.; Iteman, I.; Michault, A.; Murri, S.; Frangeul, L.; Vaney, M.C.; Lavenir, R.; Pardigon, N.; Reynes, J.M.; Pettinelli, F.; et al. Genome Microevolution of Chikungunya Viruses Causing the Indian Ocean Outbreak. PLoS Med. 2006, 3, e263. [CrossRef] [PubMed]

26. Wang, W.K.; Chen, H.L.; Yang, C.F.; Hsieh, S.C.; Juan, C.C.; Chang, S.M.; Yu, C.C.; Lin, L.H.; Huang, J.H.; King, C.C. Slower Rates of Clearance of Viral Load and Virus-Containing Immune Complexes in Patients with Dengue Hemorrhagic Fever. Clin. Infect. Dis. 2006, 43, 1023-1030. [CrossRef] [PubMed]

27. Musso, D.; Gubler, D.J. Zika Virus. Clin. Microbiol. Rev. 2016, 29, 487-524. [CrossRef] [PubMed]

28. Klitting, R.; Fischer, C.; Drexler, J.; Gould, E.; Roiz, D.; Paupy, C.; de Lamballerie, X. What Does the Future Hold for Yellow Fever Virus? (II). Genes 2018, 9, 425. [CrossRef]

(C) 2019 by the authors. Licensee MDPI, Basel, Switzerland. This article is an open access article distributed under the terms and conditions of the Creative Commons Attribution (CC BY) license (http://creativecommons.org/licenses/by/4.0/). 